\title{
A teoria do esforço de Maine de Biran como contraposição à impossibilidade da cientificidade da psicologia em Kant
}

Maine de Biran's theory of effort as a counterpoint to the impossibility of the scientificity of psychology in Kant

\author{
ANDRÉ RENATO OLIVEIRA (iDa
}

\section{Resumo}

Este artigo propõe demonstrar uma contraproposta oriunda da filosofia de Maine de Biran à posição de Kant quanto à impossibilidade da cientificidade da psicologia. Para fundamentarmos essa tese, estabeleceremos uma interlocução com a filosofia de Maine de Biran, em especial sobre a sua ideia do "esforço, fato primitivo", que nada mais é do que a apercepção interna imediata de si; um sentimento íntimo de nossa existência. Apresentaremos como é a partir da interpretação da possibilidade do existir, oriunda do cogito cartesiano, que Kant justifica o perigo da conversão do sujeito lógico e de seus predicados em substância (conforme é destacado por ele nos Paralogismos). Kant entende que Descartes substancializa o "eu penso", que constitui e unifica todas as nossas representações. Todavia, demonstraremos neste trabalho, fundamentados pela filosofia de Maine de Biran, que o erro de Descartes foi o de equiparar o "eu" da consciência de si com à alma substância. Descartes não distingue o eu da alma, ou seja, o eu que pensa da alma como simples capacidade de pensar. Consequentemente, ao situar uma substância ao nível da experiência, Descartes acaba por promover uma confusão quanto às duas maneiras de existir: uma existência em si e outra existência para si, visto que elas não encerrariam o mesmo ser. Confirmada essa questão, mostraremos que o eu do esforço biraniano é capaz de propiciar a consciência de si para si. Realizada tal tarefa, corroboraremos que a posição tomada por Kant diante das formas do existir é o que lhe impossibilita captar a experiência interna do esforço em sua originalidade irredutível, substituindo o ato do eu, inseparável da afirmação de uma existência externa, pela substância pensante, e disso decorre a impossibilidade de 0 filosofo alemão pensar a psicologia como ciência da alma, diferindo-a das ciências naturais, fato que o coíbe de elaborar uma doutrina do sentido interno, algo que, demonstraremos aqui, Maine de Biran faz com excelência.

\footnotetext{
a Universidade Federal de São Carlos (UFSCar), São Carlos, SP, Brasil. Doutor em Filosofia, e-mail: andrerpro@hotmail.com
} 
Palavras-chave: Maine de Biran. Kant. Psicologia.

\begin{abstract}
This paper to demonstrate how Kant's position regarding the impossibility of the scientificity of psychology is counter-proposed. However, we will demonstrate in this work, based on Maine de Biran's philosophy, that Descartes' mistake was to equate the self of self-consciousness with the substantial soul. Consequently, by situating a substance at the level of experience, Descartes ends up promoting a confusion regarding the two ways of existing: an existence in itself and an existence for itself, since these would not contain the same being. Once this question is confirmed, we will bring the concept of the Kantian subject to a closer dialogue with that of the self of the biranian effort, in order to show how the latter is capable of promoting self-awareness for itself. Our objective then is to corroborate through this dialogue that the position taken by Kant before the forms of existing, making it impossible for him to capture the internal experience of the effort in its irreducible originality; replacing the act of the self, inseparable from the affirmation of an external existence, by the thinking substance, and this results in Kant's inability to think of psychology as a science of the soul, differing it from the natural sciences, preventing him from elaborating a doctrine of internal meaning, something that we will demonstrate here Maine de Biran does with excellence.
\end{abstract}

Keywords: Maine de Biran. Kant. Psychology.

\title{
Introdução
}

Nos Paralogismos, a tese da substancialidade é formulada por Kant $(\mathrm{KrV}$, A. 348) da seguinte forma, "eu sou enquanto ser pensante o sujeito absoluto de todos os meus julgamentos possíveis e esta representação de mim mesmo não pode servir de predicado a nenhuma outra coisa. Logo eu sou enquanto ser pensante (enquanto alma) uma substância". É a partir desta exposição que Kant inicia a sua crítica do primeiro paralogismo da psicologia pura.

Destes elementos provêm, unicamente por composição, todos os conceitos da psicologia pura, sem reconhecer minimamente qualquer outro princípio. Esta substância, considerada apenas como objeto do sentido interno, dá o conceito da imaterialidade; como substância simples, o da incorruptibilidade; a sua identidade, como substância intelectual, dá a personalidade; e estes três elementos em conjunto, a espiritualidade [...] (KANT KrV A.345 B403).

Esta argumentação é “contaminada”, segundo Kant, por quatro paralogismos, e um destes é aquele que coloca a alma como substância, que é, por sua vez, a causa de todos os outros; refutá-lo leva à ruína completa a psicologia racional, ou seja, para Kant, a psicologia racional ou pura não poderia fundamentar os fenômenos da 
experiência interna numa alma substancial ${ }^{1}$. Por isso, Kant afirma que os conhecimentos da psicologia racional são falsos, pois partem da incompreensão epistemológica de que o eu pode ser tomado como uma coisa em si mesma e ser conhecido através do pensamento puro. O silogismo sob o qual Kant (KrV. B411) funda este paralogismo é o seguinte: “o que só pode ser pensado como sujeito, só como sujeito existe, e é, portanto, substância. Ora, um ser pensante, considerado unicamente como tal, só pode ser pensado como sujeito. Portanto, também só existe como tal, isto é, como substância". Disto resultaria nossa incapacidade em saber se este eu substância é material ou imaterial, mortal ou imortal, pois todos estes atributos pressupõem a substancialidade do en, e os argumentos pelos quais tentamos estabelecê-los não passam de paralogismos.

Mas o que vem a ser precisamente, então, esta noção de eu substância, sobre a qual está fundada toda a psicologia racional? E mais: Kant, está correto quanto à impossibilidade de pensarmos o eu em si mesmo? Há no idealismo transcendental um desaparecimento da apercepção imediata interna do eu? Kant não estaria transformando o sujeito num mero suporte passivo das formas do pensamento? Estas perguntas são relevantes e vamos nos dedicar a elas.

\section{O eu pensoe a psicologia racional}

Guillermit (2008, p. 139) destaca que Kant introduz um conceito que não existia em sua lista de conceitos transcendentais. Esta é a expressão eu penso, com ela a delicada tarefa de "dissipar a ilusão"2. Kant (KrV A344 B402) é claro ao afirmar que o eu penso é, pois, o único texto da psicologia racional de onde esta deverá extrair toda a sua sabedoria. No texto Princípios metafísicos da ciência da natureza há uma afirmação reveladora. Kant (MAN AA4:11-12) assevera que a psicologia (teoria da alma) "não pode jamais tornar-se mais do que uma teoria natural histórica do sentido interno [...], ela será uma descrição natural da alma, mas nunca irá tornar-se uma ciência da alma, nem mesmo uma teoria psicológica experimental”. Destaco aqui duas questões

\footnotetext{
${ }^{1}$ É notório que, para Kant, a aplicabilidade da categoria de substância à alma implicaria uma confusão entre o eu transcendental com o eu transcendente.

2 Termo de Kant usado no prefácio da Crítica da Razão Pura (KrV) A. XIII. Lembremos que a psicologia racional, originando-se a partir do cogito, "comete paralogismos".
} 
fundamentais; primeiro: conforme a afirmação de Kant, a psicologia não poderá ser uma ciência da alma; segundo: mediante os fatos ali destacados, a psicologia não entraria no projeto crítico kantiano, ou seja, deste está excluída a elaboração de uma doutrina do sentido interno, o que caracteriza, em certa medida, o aparente descrédito de Kant quanto à investigação do sentido interno, mas, mais do que isso, tal negligência impossibilitará Kant de obter avanços nesta matéria ${ }^{3}$. Observemos as palavras enunciadas por Kant:

[...] embora a psicologia racional não apresente utilidade alguma para o alargamento do conhecimento [...], não se lhe pode, contudo, recusar uma importante utilidade negativa. Para que necessitamos de uma psicologia simplesmente fundada nos princípios puros da razão? Sem dúvida que é, sobretudo, com a intenção de pôr o nosso eu pensante ao abrigo do perigo do materialismo. Mas consegue-o o conceito racional que demos do nosso eu pensante. Com efeito, bem longe de, com este conceito, se manter algum receio de que, suprimindo a matéria, se veja desaparecer todo o pensamento e mesmo a existência de seres pensantes, antes é claramente indicado que, se faço desaparecer o sujeito pensante, deve necessariamente ficar suprimido todo o mundo dos corpos, como se nada fosse a não ser o fenômeno na sensibilidade do nosso sujeito e um modo de representação desse mesmo sujeito (KANT, KrV A.382-383).

É evidente a preocupação de Kant (AK XII, 31) em proteger o eu pensante (lógico-transcendental) dos perigos do materialismo, contudo, tal proteção incide diretamente em sua concepção sobre as formas do existir, impossibilitando-o de captar a experiência interna: "[...] a alma só pode ser percebida pelo sentido interno, e só pode perceber o corpo (interiormente e exteriormente) pelos sentidos externos". Mas, esta preocupação de Kant sempre foi tão evidente? Não é o que parece, se nos atentarmos aos parágrafos A.XVI e XVII da Crítica da razão pura, nos quais Kant adverte que

[...] a dedução dos conceitos puros do entendimento, foram as que me custaram maior esforço [...] esse estudo elaborado com alguma profundidade consta de duas partes. Uma reporta-se aos objetos do entendimento puro [...] a outra diz respeito ao entendimento puro em si mesmo, do ponto de vista da sua possibilidade e das faculdades cognitivas em que assenta; estuda-o, portanto, no aspecto subjetivo (KANT, KrV A.XVIXVII, grifos nossos).

Nesta passagem, há uma afirmação que parece contradizer a preocupação destacada por Kant anteriormente. Ocorre aqui uma clara preocupação com a investigação sobre o aspecto subjetivo do entendimento puro. Curiosamente, na

\footnotetext{
${ }^{3}$ Na psicologia ou no campo psicológico. 
segunda edição da obra, em 1787, aparece na dedução (precisamente no \$16) o eu penso e este deve poder acompanhar todas as nossas representações. Em nosso trabalho intitulado A influência de Johann Nicolaus Tetens na dedução transcendental das categorias de Kant (OLIVEIRA, 2019), debruçamo-nos na diferença e no teor psicológico que distingue as duas edições da Crítica. Poderíamos aqui discorrer longamente sobre esta questão, mas correríamos risco de nos perder e, para mantermos o foco, não nos estenderemos a esse respeito. É sabido que, em Kant ( $\mathrm{rrV}$, A78), para que o diverso (espontaneidade de nosso pensamento) torne-se conhecimento, é necessário um ato de síntese que o una. "A síntese em geral é, como veremos mais adiante, um simples efeito da imaginação, função cega, embora imprescindível, da alma, sem a qual nunca teríamos conhecimento algum, mas da qual muito raramente temos consciência”. Em outro momento, Kant (KrV A.86-B119) destaca que "[...] as impressões dos sentidos nos dão o primeiro motivo para desenvolver toda a faculdade de conhecimento e para constituir a experiência [...]". Na primeira edição da Crítica, contamos com a chamada tripla síntese, de onde se extrai a afirmação:

A consciência de si mesmo, segundo as determinações do nosso estado na percepção interna, é meramente empírica, sempre mutável, não pode dar-se nenhum eu fixo ou permanente neste rio de fenômenos internos e é chamada habitualmente sentido interno ou apercepção empírica. Aquilo que deve ser necessariamente representado como numericamente idêntico não pode ser pensado, como tal, por meio de dados empíricos. Deve haver uma condição, que preceda toda a experiência e torne esta mesma possível, a qual deve tornar válida um tal pressuposto transcendental (KANT KrV A.107).

O que nos chama atenção nestas passagens é que em todas elas contamos com o elemento indispensável à introjeção do sujeito, no entanto, não há necessariamente uma apercepção de si, visto que não há um eu fixo, para Kant. Verificamos isto desde a ideia do princípio transcendental da unidade da consciência na síntese do diverso, que Kant denomina como apercepção transcendental, até sua oposição ao simples fato de consciência empírica destacado na citação anterior. Como já dissemos, não iremos nos ocupar aqui explicitamente das diferenças entre as edições da Crítica, mas vale dizer que, após observar estes textos que tratam da apercepção transcendental, se nota, na edição de 1787, Kant ocupado com eu penso de maneira mais clara, por isso sua abordagem da psicologia racional também se torna remodelada, algo também percebido nos Paralogismos. Fato é que a psicologia racional coloca o filósofo alemão 
diante do problema da existência do eu penso. Agora, Kant tem de tratar do sujeito e do sujeito pensante, mesmo indefinido; o eu transcendental caracterizaria o desaparecimento da apercepção imediata interna do eu.

\section{O ponto de partida da psicologia Racional}

Se pensarmos, como nos propõe Guillermit (2008, p. 149) que "o ponto de partida da psicologia racional reside na transformação da unidade da apercepção em objeto do sentido interno, o leitor que seguir a Crítica suporá que esta psicologia usurpa seu título de racional, mas que esta não é mais do que empírica”. Embora Kant reconheça a questão, a interrogação aqui é se a psicologia racional fundamentaria a ciência do eu penso. Embora Kant ateste que a apercepção interna é a apercepção do eu penso, ele deixa claro esta transformação da unidade da apercepção em objeto, e que esta trata-se, por um lado, da função de um eu penso enquanto condição lógica e, por outro, de um eu penso enquanto se manifesta como acontecimento interior e como afecção do eu ${ }^{4}$.

Tem-se, assim, a ideia de que o eupenso exprime a percepção de mim mesmo, mas esta é uma posição capciosa, pois ela diz apenas que tenho uma experiência interna, conquanto seja a simples percepção en penso e não uma verdadeira apercepção de si mesmo. Embora esta posição seja falha em nos responder qual é a real pretensão da psicologia racional, podemos dizer que esta seria o conhecimento do eu. Posição essa reforçada por Kant ( $\mathrm{KrV}$ A320) na Dialética, ao afirmar que "o termo genérico é a representação em geral (repraesentatio). Subordinado a este, situa-se a representação com consciência (perceptio). Uma percepção que se refere simplesmente ao sujeito, como modificação do seu estado, é sensação (sensatio); uma percepção objetiva é conhecimento (cognitio)". Observemos que neste momento a ideia predominante é a de que a representação eu é uma simples consciência que acompanha os conceitos, ainda que já constatemos nesta fórmula o gérmen da famosa premissa ("о eu penso deve poder acompanhar as minhas representações”) posta na segunda edição. Esta diz apenas que o eu não pode ser vazio de conteúdo, mas não demonstra uma consciência de si satisfatória, isto é, capaz de sustentar a existência do eu que preencha

\footnotetext{
${ }^{4}$ Cf. Guillermit, 2008, p. 150.
} 
este vazio. $\mathrm{Na}$ Analítica, ao distinguir fenômenos e noumenon, Kant deixa transparecer ainda mais esta questão:

Todas as nossas representações estão, de fato, reportadas pelo entendimento a qualquer objeto e, uma vez que os fenômenos não são outra coisa que representações, o entendimento refere-as a algo como objeto da intuição sensível; porém esse algo é, nesta medida, apenas o objeto transcendental. Este significa, porém, um algo $=\mathrm{x}$, do qual não sabemos absolutamente nada, nem em geral podemos saber (segundo a constituição do nosso entendimento), e que pode servir apenas, a título de correlato da unidade da apercepção, para unificar o diverso na intuição sensível, operação pela qual o entendimento liga esse diverso no conceito de um objeto (KANT, KrV A.250).

É notória a contribuição desta passagem para compreendermos que, para Kant, a psicologia racional não pode ser ciência, pois ela não pode ter conhecimento do eu penso enquanto objeto. Embora tenhamos aí um problema lógico, o filósofo ressalta que a consciência de si é a condição necessária da unidade da experiência. Contudo, apontamos aqui para uma passagem significativa da Deducão, na qual Kant destaca que:

Venham as nossas representações de onde vierem, sejam produzidas pela influência de coisas externas ou provenientes de causas internas, possam formar-se, a priori ou empiricamente, como fenômenos, pertencem, contudo, como modificações do espírito, ao sentido interno e, como tais, todos os nossos conhecimentos estão, em última análise, submetidos à condição formal do sentido interno, a saber, ao tempo, no qual devem ser conjuntamente ordenados, ligados e postos em relação. E esta é uma observação geral que se deve pôr, absolutamente, como fundamento, em tudo o que vai seguir-se (KANT, KrV. A.99).

De fato, ele pode distinguir o eu penso problemático da psicologia racional do cogito cartesiano, que contém a percepção de uma existência, e evitar o aspecto empírico da proposição eu penso. Heimsoeth (1966, p. 85) entende que "o conceito de eu penso kantiano não deve ser confundido com o eu penso cartesiano, pois, para o último, este é um objeto, um sujeito real; já para Kant, o eu é uma abstração”. Vamos nos deter nesta questão por ora. Conforme é destacado pelo próprio Kant, a psicologia pura ou racional distingue-se da psicologia empírica que repousa sobre o testemunho da consciência e não passa de uma forma de fisiologia do sentido íntimo; já a racional repousaria sobre a razão pura, ou seja, sobre os conceitos transcendentais e não admite nada de empírico. Disto decorre a ilusão da razão, ou seja, pensar que se pode alcançar, pela reflexão, sem recorrer à experiência, um conhecimento objetivo sobre o eu: 
Se o fundamento do nosso conhecimento racional puro dos seres pensantes em geral fosse algo mais do que o cogito, se nos socorrêssemos também das observações acerca do jogo dos nossos pensamentos e das leis naturais do eu pensante, que daí se extraem, resultaria então uma psicologia empírica, que seria uma espécie de fisiologia do sentido interno e talvez pudesse explicar os fenômenos deste, mas que nunca serviria para descobrir as propriedades que não pertencem à experiência possível (como as da simplicidade), nem para nos instruir, apodicticamente, sobre algo referente à natureza dos seres pensantes em geral; não seria, pois, uma psicologia racional (KANT, KrV, B.406).

Permanece, assim, a pendência em demonstrar que o cogito é um julgamento puro de todo empirismo e de toda a apercepção de consciência, mas Kant não o faz. O que Kant nos mostra é que o eu penso deve ter a característica de servir de princípio ao raciocínio transcendental e à ciência racional do serpensante, oferecendo-nos apenas uma suposição, isto é, a suposição de um eu penso puro de toda consciência, um en penso abstraído, que gera um en existo igualmente abstraído, ou seja, um eu vazio de conteúdo. Lembremos da passagem destacada anteriormente: "Por este eu, diz Kant, ou seja, para a coisa que pensa, nada é representado, exceto um sujeito transcendental do pensamento = x." ${ }^{\text {. }}$. Heimsoeth (1966) está correto em sua colocação, pois o fundamento da psicologia racional é uma abstração e o eu ao qual esta abstração conduz é um $x$, em Kant. Eis um ponto fundamental que desejo destacar novamente, corroborando o fato de que não temos uma apercepção de si, mas sim um eu incognoscível.

É no quarto Paralogismo que Kant mostra que a existência de minha alma pode ser percebida de maneira imediata pelo eu; é justo dizermos que nós não podemos, desse modo, perceber imediatamente que somos (nós mesmos), por conseguinte nossa própria existência. Sendo assim, Descartes restringe com razão toda percepção à proposição $e u$ (enquanto ser pensante) sou. Kant deixa claro sua posição ao afirmar que

o eu penso é, como já foi dito, uma proposição empírica e contém em si a proposição eu existo. Não posso, contudo, dizer "tudo o que pensa existe", pois então a propriedade do pensamento tornava todos os seres que a possuem, noutros tantos seres necessários. Por isso, a minha existência também não pode considerar-se deduzida da proposição eu penso, como Descartes julgou (pois de outra forma devia supor-se, previamente, "tudo o que pensa existe"), mas é-Ihe idêntica (KANT, KrV B.422).

Nota-se nesta passagem ainda, uma afirmação quanto ao fato de que não "posso deduzir minha existência da proposição eu penso" e "eu penso contém em si a proposição eu existo", o problema é que Kant parece não compreende tratar-se de

${ }^{5}$ Cf. Cousin, 1864, p. 151. 
existências distintas e funda toda sua crítica sem considerar este fato. Caracterizamos este como o "grande equívoco de Kant", sobre o qual iremos refletir com o auxílio da filosofia de Maine de Biran.

\section{Maine de Biran: crítico de Kant ou o "Kant Francês"?}

Constatamos que a origem das questões tem um denominador comum, o cogito cartesiano. Partindo da interpretação do cogito, realizada por Biran, é detectável uma reformulação proposta pelo filosofo francês. Para Biran o cogito é a expressão mais genuína da existência pessoal. $\mathrm{O}$ eu só pode ser cultivado em sua pureza pelo sentido íntimo, enquanto a tentativa de representá-lo só faz deformar sua natureza. A importância que Biran atribui ao cogito cartesiano dá-se pelo reconhecimento de que Descartes foi o primeiro a buscar na própria consciência o princípio de todo conhecimento. Mas embora esta louvável realização tenha de ser vangloriada, advém desta também uma crítica. Descartes não soube conservar nem a pureza nem seu pleno valor de certeza; o cogito se desnatura instantaneamente em sua formulação. Eis a crítica de Biran: o que significa dizer “eu penso, logo sou uma coisa pensante?”. É legítimo concluir, a partir da consciência, que temos de pensar a existência de uma substância da alma? Com que direito deduzimos da atividade do eu, que é imediatamente capturada pelo sentido íntimo, a existência que vai além do fato primitivo e não está contida nele de maneira nenhuma?

Se Kant detectara um paralogismo no entimema cartesiano, Biran deriva deste consequências totalmente originais. Há um silogismo implícito na base do cogito que Biran (TISSERAND, 1932, v. VII, p. 124-125) destaca, afirmando que "eu penso, eu existo para mim mesmo... Ora, tudo que pensa ou sabe que existe, existe absolutamente como coisa pensante fora do pensamento. Logo eu existo substancialmente".

A originalidade de Biran está em evidenciar que os dois eu não possuem o mesmo significado. O primeiro é um sujeito fenomênico; o segundo, um sujeito real e absoluto. Parafraseando Gouhier (1947, p. 280), para Biran, Descartes não distingue o eu e a alma, ou seja, não há uma distinção entre o eu que pensa e a alma que é uma simples capacidade de pensar. Descartes definiria então a alma como substância 
pensante, sem se afastar da consequência lógica de que a alma sempre pensa. Nas palavras do mesmo Gouhier (p. 280), a alma torna-se, assim,

um eu absoluto, noção contraditória, uma vez que o eu é essencialmente relativo. Disto segue que a primeira correção a se fazer do cartesianismo consiste em reconhecer que o eu sou do eu sou (je suis) pensante e aquele do eu sou absolutamente não são o mesmo eu (je) porque eles não contem o mesmo ser.

Conforme o comentador, Descartes não enxerga em seu cogito o silogismo, ao tomar como premissa maior "tudo que pensa existe". Por outro lado, Biran inova e busca atingir o ser em si, excluindo toda marcha discursiva por meio da introspecção do espírito. Biran demonstrara que não é necessário excluirmos a psicologia do sujeito pensante, pois o erro de Descartes foi ter posto a substância no mesmo nível da experiência. Discorreremos com mais acuidade sobre esta questão, quando apresentarmos a psicologia de Maine de Biran. Por agora, vamos nos deter na substancialidade do eu e sua conotação paralogística e a resolução biraniana.

Retomando a questão, o paralogismo torna-se possível então graças ao duplo sentido da palavra existir, que nos confunde. Esta palavra pode referir-se tanto à existência subjetiva do $e u$, que é capturada na singularidade de sua ação, quanto à existência objetiva e anônima aplicada indiferentemente a cada coisa. É claro que se trata de posições distintas. Para solucionar este impasse, Biran aponta para a pureza do fato primitivo, que se exprime nos dois juízos (eu penso, eu existo) de maneira idêntica. Dito isto, sustentamos que toda a força do entimema cartesiano está intrinsicamente ligada ao pronome eu no qual já está inclusa a existência pessoal. O problema estaria, justamente por isso, na confusão entre existência subjetiva e objetiva, na formulação lógica do princípio cartesiano. Nas palavras do próprio Maine de Biran:

O princípio é evidente e oferece um fundamento real e sólido a toda consciência humana, mas isto exige uma condição: que não haja outra qualidade além do fato de consciência, ou da existência no momento presente sentida, expressa pela primeira parte do entimema: cogito. Se acrescentarmos um elemento que não lhe estava contido, na segunda parte, isto é, na conclusão ergo sum, ou seja, acrescentando-lhe a noção de substância [...] a dúvida recomeça (TISSERAND, 1932, v. VII, p. 281).

Maine de Biran inicialmente rejeita a dúvida metódica cartesiana, pois entende que esta dúvida não estaria em nosso poder. Quanto a certas verdades evidentes por si mesmas, Descartes emprega — infelizmente — a denominação "verdades inatas", 
aderindo à doutrina do inatismo de certas ideias. No entanto, segundo Maine de Biran, as verdades necessárias e evidentes por si mesmas são as verdades matemáticas, depois a existência dos corpos. Para nos ajudar a elucidar a questão, tomemos como exemplo o que Biran considera ao deparar-se com a ideia cartesiana das ilusões subsequentes a certas sensações. Citamos novamente Maine de Biran:

Não é verdade que possamos reconhecer que não sentimos o que acreditávamos ter sentido durante o sono. Ao contrário, as sensações que a alma experimenta durante 0 sono realmente ocorreram. A ilusão consiste apenas em acreditar ou julgar que os objetos ou as causas às quais estas sensações internas se relacionam estão presentes aos sentidos, sendo que não o estão realmente. Mas este julgamento não é a sensação (BIRAN a pud BERTRAND, 1887, p. 77).

Destacamos aqui a observação de Biran sobre o que ele caracteriza como "erro de Descartes”. Quando Descartes pretende encontrar no fato do pensar a base de toda certeza, Eu penso, logo existo (je pense, donc je suis) ocorre uma confusão, pois Descartes aproxima o fato transitório do pensamento com a certeza do eu permanente. Descartes demonstra somente o primeiro (je pense) e afirma que o segundo (je suis) é sua consequência. Quando ele diz eu sou (je suis), confunde a noção abstrata de seu ser com o sentimento concreto de sua existência. O problema é que estas são duas coisas totalmente distintas: a noção abstrata é posterior ao sentimento do $e \mathfrak{u}$, o fato primitivo compreende não só o pensamento, mas a individualidade por completo.

Esta posição de Biran com relação àquela de Descartes é fundamental, porque em Biran o fato primitivo é o eu completo, objeto da apercepção interior, fato da consciência. Descartes não percebe que o fato da consciência compreenderia tal completude e faz do conhecimento do corpo o objeto da imaginação.

Embora esclarecida a objeção de Biran a Descartes, podemos refletir se esta o aproxima de Kant, caracterizando-o como o "Kant francês"; e a responderemos da seguinte maneira: se Biran (TISSERAND, 1932, v. VII, p. 140) contesta veementemente Descartes, sua crítica a Kant é ainda mais severa. Vamos a ela: "Apoiando-se mais sobre a abstração do que sobre a reflexão Kant se ocupa da classificação ou da ordem lógica dos instrumentos da consciência, muito mais do que da análise real dos elementos da própria consciência”. Ao não se atentar para o fato primitivo, Kant "merece mais do que Descartes ou Leibniz a censura, por ter suposto que não existe, sem esclarecer o que há ali” (p. 143). Kant é considerado por Biran 
como um dos seguidores da escola que faz de Descartes seu chefe, por consequência, seu sistema pertence àqueles que enveredam numa "tentativa infeliz" de encontrar a origem da consciência fora da consciência do eu.

Temos de reconhecer, contudo, que a crítica de Biran funda-se em seu conhecimento indireto do kantismo (Biran não dominava o alemão e, por isso, não leu os trabalhos mais significativos de Kant), razão pela qual foge a Biran o verdadeiro significado da filosofia crítica. Apesar disso, a prospectiva dos filósofos é essencialmente diversa, e seus interesses investigativos parecem realmente não coincidir. Há comentadores tanto alemães, como König (1889), quanto franceses, como Lachelier (1871), que afirmam que "Maine de Biran é o nosso Kant". De fato, contamos com similaridades, e embora o texto até aqui já as tenha evidenciado em certa medida, sejamos mais explícitos.

Ambos estão sob a influência do racionalismo/empirismo e buscam resolver o conflito entre as duas tendências. Outra coincidência é a afirmação da primazia do eu no fato cognoscitivo: tanto para Kant quanto para Biran não há consciência sem um elemento subjetivo ou formal. A respeito do conceito de matéria também há certa analogia; tanto a sensibilidade kantiana quanto a afetividade biraniana permanecem sob o limiar da consciência, todos estes dados constituem um caos sem nexo ou ordem. Apenas o eu, admitem os filósofos, pode mudar a matéria disforme da sensação, ou seja, estabelecer a relação entre o dado sensível, atribuindo-lhe a um sujeito. A mesma concordância existe quanto à origem subjetiva do elemento formal do conhecer. Todavia, se, por um lado, contamos com semelhanças, estas não devem nos ludibriar, visto que há entre Biran e Kant divergências substanciais: por exemplo, para Biran sujeito e eu coincidem sem problemas e a consciência que temos de nós mesmos no esforço constitui uma experiência privilegiada de ordem superior à da experiência externa, na qual nos é dada instantaneamente a noção fundamental do conhecer. Kant, ao contrário, distingue o sujeito do eu transcendental, porque o eu que é dado instantaneamente à consciência não constitui de modo algum um fato privilegiado que possa servir para explicar os outros fatos, carecendo ele mesmo de explicação. Outra divergência basilar é a de que o eu biraniano é concreto, enquanto tomado em sua vigência mediante o esforço voluntário, este é dado numa experiência direta e imediata que o constitui como pessoa (singular); já o eu transcendental kantiano 
é abstrato, isto é, forma pura, posta além e, portanto, fora da tomada de consciência e consequentemente privado da forma pessoal ${ }^{6}$.

O comentador Gouhier (1947, p. 269) vai ainda mais além sobre as divergências e sustenta que o biranismo opõe-se ao kantismo em suas teses mais fundamentais: "o $e \mathfrak{u}$ do esforço descobre as formas do pensamento refletindo sobre sua própria atividade: o sujeito kantiano não passa de um suporte passivo da formas". Ainda conforme este comentador, para Biran a teoria do conhecimento é uma ciência dos fatos da consciência, e não — como propõe Kant — uma espécie de lógica. Forma e matéria designam dois elementos reais: a sensação kantiana só é dupla por uma distinção nominal, e acrescenta que "a matéria sensível desfruta de uma existência concreta fora das formas, mas, segundo Kant, a própria experiência se encontra definida por esta união” (p. 269). Atento às divergências, Gouhier (1947, p. 269-270) ainda critica fortemente a fala de Lachelier de que Biran seria o "Kant francês", afirmando que seria "mais aceitável pensar que o biranismo é isento do kantismo". Curiosamente, numa nota de rodapé de seu texto Les conversions de Maine de Biran (1947), Gouhier (p. 270, nota I) destaca: “Jules Lachelier me disse um dia que Maine de Biran pode nos desobrigar de passar por Kant...”. Por fim, sustentamos, atrelados a essa posição de Gouhier, que Biran não desejava ser kantiano, mas sim, em certa medida, o evita, pois, se a Crítica da razão pura "traz à tona um sujeito transcendental portador das formas e categorias, um sujeito psicológico, apreendido na experiência interior, um sujeito ontológico, a presença do primeiro torna inacessível a experiência do segundo" (GOUHIER, 1947, p. 270).

Atestadas as divergências, estas podem nos orientar à crítica de Biran. Se, para Kant, Descartes substancializa o eu penso que constitui e unifica todas as nossas representações, para Biran o erro de Descartes foi o de equiparar o eu da consciência de si com a alma substância. Ao situar uma substância no nível da experiência, Descartes acaba por promover uma confusão quanto às duas maneiras de existir: uma existência em si e uma existência para si, visto que estas não encerrariam o mesmo ser. Nas palavras de Biran, embora Kant tenha distinguido "os sujeitos", ele não atentou às suas formas de existência. Nesse sentido, Gouhier (1947, p. 279) sustenta que, para

\footnotetext{
${ }^{6}$ Cf. Ghio, 1962, p. 129.
} 
Kant, o cogito aplica a uma forma vazia a categoria de substância, ou seja, Descartes ignora as condições da experiência, sua filosofia é carente de uma epistemologia. Já para Biran, o sujeito unificante não é uma forma vazia, a substância não é uma categoria e não há formas da sensibilidade. Assim, para este último, o real paralogismo cometido por Descartes significa passar muito rapidamente pela experiência, e, por isso, sua filosofia carece de uma psicologia.

Dito isto, podemos estabelecer que, para Biran (Tisserand, 1932, v. VII, p. 130), é Descartes que nos ensina a realizar a importante distinção entre os dois valores do termo existir, ou da existência objetiva e subjetiva, relativa e absoluta, que infelizmente se encontram confundidas sob a forma lógica de seu princípio. Não é segredo que a teoria do sentido interno (kantiana) nos tem ofertado um eupassivo, um eu-fenômeno, e o eu, que nos permanece inexplicável. Falamos obviamente do eu-sujeito (lembremos $=x$ ), idêntico à apercepção. A apercepção (ou seja, o eu penso) é uma consciência do eu, mas não como ela nos aparece na intuição interna ou como fenômeno, nem como somos em nosso ser em si enquanto noumenon; ela nos mostra apenas que somos ou que existimos, isto é, a representação "eu sou” ou "eu existo" é um saber intelectual que nos mostra a existência do nosso eu. Isto não só comprova o que afirmamos anteriormente, mas também que o criticismo é carente em precisar nossa existência, ou melhor, a consciência (percepção) de nossa própria existência ${ }^{7}$.

\footnotetext{
7 Para Kant "[...] sentido interno (§ 6), a saber, que este nos apresenta à consciência, não como somos em nós próprios, mas como nos aparecemos, porque só nos intuímos tal como somos interiormente afetados..." (KANT KrV B153). A questão é que para Kant, no sentido interno, a pessoa não é consciente de como é em si mesma, apenas enquanto aparência. "[...] saber o que sejam as coisas em si, pois nunca uma coisa se poderá apresentar a mim a não ser no fenômeno" (KANT KrV A277 B333). A respeito do pensar a si mesmo como sujeito: "porém, este eu é tão pouco intuição como conceito de qualquer objeto, mas apenas a simples forma da consciência, que pode acompanhar as duas espécies de representações e elevá-las, assim, ao nível de conhecimentos, com a condição de ainda ser dada na intuição qualquer outra coisa que forneça matéria para a representação de um objeto. Cai por terra, assim, toda a psicologia racional como uma ciência que ultrapassa todas as forças da razão humana e nada nos resta senão estudar a nossa alma, seguindo o fio condutor da experiência, e mantermo-nos dentro dos limites das questões que não vão para além do terreno onde a experiência interna possível pode dar-lhe o seu conteúdo" (KANT KrV A382) e "do mesmo modo, a simplicidade de mim próprio (como alma) não é efetivamente deduzida da proposição 'eu penso', mas há já a primeira em todo o pensamento. A proposição: eu sou simples deve considerar-se expressão imediata I da apercepção; igualmente o pretenso raciocínio cartesiano, cogito, ergo sum, é, de fato, tautológico, pois o cogito (sum cogitans) exprime imediatamente a realidade. Eu sou simples não significa, porém, senão que esta representação eu não contém em si a mínima diversidade e que é uma unidade absoluta (embora puramente lógica)" (KANT KrV A355).
} 
Isso posto, avançaremos agora com Biran na demonstração de como a teoria do eu do esforço biraniana, é capaz de propiciar a consciência de si para si, a fim de corroborar que a posição kantiana quanto às formas do existir impossibilitou-lhe captar a experiência interna do esforço em sua originalidade irredutível. Substituiu o ato do eu, inseparável da afirmação de uma existência externa, pela substância pensante e, por consequência disso, estava impedido de pensar a psicologia como ciência da alma, diferindo-a das ciências naturais, coibindo-o de elaborar uma verdadeira doutrina do sentido interno.

\section{A psicologia de Maine de Biran}

Maine de Biran (TISSERAND, 1932, v. XII, p. 14) está preocupado em estabelecer os "verdadeiros fundamentos da psicologia" e a "utilidade prática de uma ciência até hoje muito descreditada". Contudo, a série de divergências trazidas pelas mais variadas escolas "é o maior obstáculo à descoberta do verdadeiro princípio psicológico” (p. 405). Nestas, temos o ponto de vista ontológico que começa pelo absoluto; a alma pensante, mas este absoluto, "contraria a tudo o que pode oferecer a especificidade de um fato, e em compreender o eu em si mesmo [...]" (p. 405); e o ponto de vista empírico que se inicia pela sensação e postula um sujeito substancial idêntico.

Embora contemos com estas duas tendências, Maine de Biran confessa procurar "em vão nas duas vertentes o que chamo de princípio ou fundamento da ciência, que não pressupõe de imediato uma ciência adquirida ou incutida; mas no lugar de princípios, encontro sempre paralogismos" (TISSERAND, 1932, v. XII, p. 476). Observemos que tanto os metafísicos puros, quanto os empiristas empregam a ideia de causa, mas esta é inerente a alma a título de forma ou de ideia inata? Desta questão advém a ideia de "que, se concebo tão claramente uma causa eficiente, porque tenho sempre uma noção tão obscura [...] da substância da alma em si?” (p. 480). "Como eu sei que tenho uma alma e que toda a ideia de causa dela deriva?" (p. 480). Parafraseando Biran, podemos perguntar se é possível certificar que os empiristas podem responder aos terríveis argumentos de Hume? Referimo-nos àqueles segundo os quais não haveria causas, mas o hábito por ver a repetida ligação entre as coisas e 
os fatos; ou ainda pensar como Kant, que a causalidade é uma forma; mas se assim o fizermos, no que esta se diferenciaria do hábito? ${ }^{8}$.

Leibniz, nos Novos Ensaios, revela que gostaria de descobrir como saberíamos que há seres, se não nos reconhecemos como nós mesmos. A esse respeito, Maine de Biran propõe, então,

transformar a questão ontológica precedente nesta outra questão, que é realmente fundamental à ciência: como poderíamos nós saber se há causas, se não soubéssemos previamente ou não apercebêssemos imediatamente que somos causa, dito de outro modo, se o eu não é causa por si mesmo, se sua causalidade primitiva não é idêntica à sua existência apercebida (TISSERAND, 1932, v. XII, p. 408).

Desta posição surgirão as seguintes consequências": entre o ser e a consciência das coisas, "a alma deve ser concebida como é em si mesma", mas, para tanto, Biran reconhece ser necessário um intermédio ou um intermeio. Trata-se do "fato primitivo através do qual a alma manifesta-se a si mesma". Advertimos, que para Biran, esta manifestação interior não é aquela da "substância sempre concebida objetivamente, mas sim a da força ou da causa que é originariamente subjetiva" noutras palavras, "a partir da consciência do eu como causa entenderemos e conceberemos as outras causas [...]” (TISSERAND, 1932, v. XII, p. 409). Mesmo na esteira do pensamento biraniano, esta operação é realizada por um julgamento sintético, contudo este não é nem a priori nem a posteriori. Não é a priori, uma vez que "é impossível concebê-lo antes do fato primitivo", nem a posteriori, no sentido de que a experiência repetida seria necessária para confirmá-lo, uma vez que “a causalidade do eu é certa já na primeira experiência imediata [...]” (p. 409). Notamos, já num primeiro momento, a nova abordagem da questão do eu que Biran oferece, destacando como pressuposto fundamental o conceito de fato primitivo do sentido intimo, e como a introjeção deste conceito possibilita, obviamente dentro da concepção biraniana, atingir a cientificidade da qual carece a psicologia.

Atentando a esta nova descoberta de Biran, destacamos que a condição inicial para que haja o "fato" é, segundo Biran (TISSERAND, 1932, v. VII, p. 14-15), “o sentimento de nossa própria existência (individual) e aquela de qualquer objeto ou modificação que conflui com esta existência sendo este [...] separada dela [...]”. Tal

\footnotetext{
${ }^{8}$ Cf. TISSERAND, 1932, v. XII.
}

${ }^{9}$ Cf. Voutsinas, 1975, p. 91. 
sentimento de existência é chamado na psicologia de consciência. Biran destaca que um fato nada é se não for conhecido, ou seja, se não houver um sujeito particular e permanente que o conheça; diferente de Kant, temos em Biran um sujeito permanente. Nesse sentido, as sensações diferem do sentido posto por Condillac e por Bonnet, isto é, não há ainda um fato, pois ainda não há eu. Nestes autores, o indivíduo não se distingue da coisa ou do objeto. Tomemos como exemplo a análise da estátua de Condillac, e veremos que ela é originalmente uma tábua rasa, sensível, e que, mesmo após ter recebido o "odor de rosas", e este ser um fato para o expectador, não o é para a estátua, porque ela não é capaz de distinguir-se deste odor. De acordo com Biran, é sobre tal distinção que repousa o fato da consciência, o qual consideramos como primitivo. O que temos aqui, além de uma concepção de vontade, nada mais é do que a distinção biraniana das existências que parte da crítica do cogito cartesiano, isto é, o ser fora de si (être hors de sol) e o ser que é (être sol). O fato primitivo não nos é, então, somente a sensação, mas a ideia da sensação que só tem lugar enquanto a impressão sensível confluir com a individualidade do eu (TISSERAND, 1932, v. XII, p. 15). O verdadeiro fato primitivo do sentido íntimo deve ter a particularidade da permanência, de relação, que não deve se estender para além dos limites da consciência, e nem admitir qualquer elemento externo (p. 15). Por outro lado, o outro elemento que forma o segundo termo desta união insolúvel permanece vazio. Contudo, Biran deixa claro tratar-se dos objetos do sentido externo (audição, visão...). Estes são diferentes uns dos outros, cada um deles associados a "mim" constituem um fato particular, mas nenhum deles "goza, exclusivamente em relação aos outros, do caráter de primazia, de constância e de indissolubilidade com o sujeito, que deve se adequar ao elemento necessário da dualidade original ou do fato primitivo do sentido íntimo" (p. 15).

Segundo Biran, mesmo os que defendem a dualidade primitiva acabam por se contradizer quando pretendem caracterizar separadamente sujeito e objeto. Mas, pensemos: se o sujeito é uno, simples e idêntico, estaríamos falando de uma abstração ou de uma existência real? A resposta é a seguinte: no caso de ser uma existência real, seria indubitável 
que nenhuma existência compreenda aquela do $e u$, que só poderia ser dada a título de fato, e sob uma ou outra destas duas relações, a saber, aquela do modo variável ou permanente a uma substância una, idêntica, ou mesmo aquela de um efeito transitório, que se inicia com uma causa durável que a introduz ou a define [...] (TISSERAND, 1932, v. XII, p. 25).

Mas isto responde qual das duas é o primitivo? De fato, não. "Noutras palavras, o eu é dado a si mesmo no fato primitivo como substância modificada, ou como causa ou força produtora de certos efeitos?” (TISSERAND, 1932, v. XII, p. 25). Quanto a essa questão, Biran, assim explica: se "encontramos em nosso espírito a ideia de substância, esta noção relativa é uma dedução distante dos fatos primitivos” (p. 25) ${ }^{10}$, pois, “embora também encontremos no espírito igualmente a noção de força, antes desta, o "sentimento imediato da força" não é outro senão aquele de nossa própria existência, do qual a atividade é inseparável” (p. 25). Isto quer dizer que a causa ou força atuante com a qual o "eu se identifica totalmente" é a vontade. Esta força é determinada ou atualizada apenas na relação com seu limite de aplicação; da mesma forma, o limite só é determinado como resistência ou inerte em relação com a força atual que o move. É o fato desta tendência que Biran chama de esforço ou ação voluntária, "e digo este esforço é o verdadeiro fato primitivo do sentido intimo" (p. 25). Como é destacado por Biran nesta passagem:

Nós podemos considerá-lo como um fato, pois a força que efetua o movimentos do corpo se distingue necessariamente do termo inerte; este fato é primitivo, pois nossos próprios sentidos externos, para se tornarem os instrumentos de nosso primeiro conhecimento [...], devem ser colocados em ação pela mesma força individual que gera o esforço; este esforço primitivo é um fato do sentido íntimo, pois encontra-se interiormente sem deixar a limitação de sua aplicação imediata, ele é o mais simples de todas as relações, uma vez que todas as nossas percepções ou representações exteriores referem-se a ele como sua condição primitiva essencial e que ele admite todas elas como elemento formal; e é o única relação fixa, invariável, sempre idêntica a si mesma, uma vez que não admite nenhum elemento variável, exterior (TISSERAND, 1932, v. VIII, p. 27-28; 32-33).

Temos, assim, esclarecida a concepção de fato primitivo do sentido íntimo biraniano, fundamento de uma verdadeira psicologia cientifica. Ademais, o fato primitivo do sentido íntimo recebe características de princípio e de fato que servem de base à noção de causalidade que está colocada "na fonte de toda ciência", no lugar da noção de substância absoluta. Por isso, "devemos ter uma outra filosofia, uma

\footnotetext{
${ }^{10}$ Vale esclarecer aqui que Maine de Biran usa o termo fato primitivo tanto no singular quanto no plural. No singular, trata-se do fato primitivo eu ( $m o l)$; no plural, trata-se das noções que, identificadas com ele, passam a ser deduzidas ulteriormente por um ato de reflexão.
} 
outra análise das sensações e das ideias, um outro sistema de formação das faculdades" (TISSERAND, 1932, v. XII, p. 28). Por este motivo é que Biran sustenta que as noções de identidade, unidade, e outras usadas pelos metafísicos não passam de deduções imediatas de um mesmo fato reproduzido sob diferentes formações abstratas, questionando o hábito. Disto advém que "toda a ciência dos princípios será resolvida nestes fatos, e que a principal função da psicologia é constatá-los em sua fonte, e deduzir todas as noções que ali se originam” (p. 32).

De forma sucinta, podemos alegar as divergências entre os sistemas apontados pouco antes como decorrentes do fato de que uns consideram os fatos primitivos como inerentes a alma e independentes da experiência, enquanto outros os deduzem das sensações. Contudo, nem um e nem outro vão além da ideia que caracteriza o fato como noção. Para Biran, não há outra forma para avançar nesta disputa senão partir do fato do sentido íntimo e balizar o sujeito à vontade que o constitui. O que Biran nos propõe como resolução à questão é que o en, ao adquirir consciência de si, constitui-se como sujeito psicológico através do esforço voluntário e " este esforço é o verdadeiro fato primitivo do sentido íntimo". Toda questão pauta-se na busca pelo que é o eu enquanto sujeito cognoscente, pois "se a individualidade tem uma origem, se o eu não é inato, então o que é ser?” (p. 32). Ora, a resposta a esta questão está no fato primitivo. Neste estaria a origem da consciência, e este é o objeto de uma experiência interna imediata. Em suma, não há intuição do $e$, e nem consciência fora dessa ação. Lembremos da asserção de Biran (TISSERAND, 1932, p. 53): “Todos os erros dos filósofos sobre este ponto advêm de que não captam a experiência interna do esforço em sua originalidade irredutível, eles substituem o ato do $e \boldsymbol{u}$, inseparável da afirmação de uma existência externa pela substância pensante [...]". Reforçamos que esse equívoco tem uma causa, que destacamos antes: trata-se do cogito cartesiano. Descartes acreditou encontrar no pensamento uma reflexão de si sobre si completamente independente de uma ação causal sobre o corpo, o que o levou a isolar a substância pensante, como coisa, da substância externa (p. 53). Biran acusa toda a filosofia moderna de ter negligenciado a experiência interna e seus dados imediatos, priorizando a experiência das coisas externas. Tal negligência impossibilitou remontar até o princípio da atividade que constitui esta existência; se esta investigação tivesse 
sido satisfatoriamente realizada, encontrá-la-íamos na experiência interna, admitindo a psicologia como a "ciência dos fatos interiores", como Biran nos descreve no texto Relações das ciências naturais com a psicologia

Chamamos psicologia a ciência que se junta inicialmente a este fato primitivo e aos seus derivados imediatos, propondo-se em fazer a análise completa dos fatos externos e designando a parte fenomênica do objeto e a parte real do sujeito; afim de reconhecer, assim, os verdadeiros elementos formais destes fatos, de trazer à sua fonte primitiva as noções de causa e de substância, justificar a realidade absoluta que nós Ihe atribuímos, em fornecer, assim, uma base à ciência dos fenômenos e garantir sua solidez apoiandoa sobre o fato evidente e irredutível da consciência ou da existência do eu (TISSERAND, 1932 , v. X, p. 128-135).

Disto decorre que o ato cognitivo é essencialmente atividade, esforço, vontade. Estas noções substituiriam as formas da sensibilidade kantiana, ou seja, o conhecimento como síntese espontânea dos dados brutos da experiência amorfa e das categorias do entendimento, tornar-se-iam menos relevantes.

Conforme, Paim (1973, p. 31), a "descoberta de Maine de Biran preenche efetivamente todas as exigências da observação introspectiva..."11. Por fim, Gouhier (1947, p. 22-23) nos faz atentar para que "Maine de Biran, julgou que o espírito humano era capaz, ao menos sobre um ponto, de alcançar o absoluto e fazê-lo objeto de suas especulações". Maine de Biran nos mostra que o conhecimento que temos de nós mesmos no sentimento de esforço é um conhecimento privilegiado, que ultrapassa o puro fenômeno e que é capaz de atingir a realidade em si, realidade esta que Kant considerava inacessível. Gouhier (GOUHIER, 1948, p. 23) acertadamente profere as seguintes palavras sobre Biran: "Maine de Biran concebe a ideia de uma

${ }^{11}$ Esta passagem é conforme Maine de Biran (apud PAIM, 1973), no livro Investigações de psicologia de Eduardo Ferreira França (1809-1857). Eduardo é provavelmente um dos primeiros no Brasil a "tratar", mesmo que indiretamente, da filosofia biraniana. Obviamente, Paim (1973) refere-se à solução biraniana de que encontramos em nosso espírito a ideia de substância; e a comprovação de que esta noção está distante dos fatos primitivos. Além disso, encontramos arraigados em nós a noção de causa ou de força; contudo, com essa noção acha-se o sentimento imediato da força, e este sentimento é o da nossa existência mesma, de que a atividade é inseparável. Não podemos nos conhecer como indivíduos sem nos sentir como causas relativas a certos efeitos ou movimentos produzidos no corpo orgânico. A esta causa ou força ativa (aplicada a mover os corpos) chamamos vontade. Contudo, a existência da força não é um fato para mim senão enquanto se exerce, e ela só se exerce enquanto pode se aplicar a um termo resistente ou inerte. Isso quer dizer que a força não é determinada ou atualizada senão em relação a seu termo (limite) de aplicação, do mesmo modo que este não é determinado como resistente ou inerte senão em relação à força atual que o move, ou tende a imprimir-lhe movimento. Ao fato desta tendência é que denominamos esforço ou ação voluntária (volição), e digo que este esforço é o verdadeiro fato primitivo do sentido íntimo. 
metafísica que se elevaria cada vez mais alto no sentido do espírito em geral, à medida que a consciência mais fundo penetrasse na vida interior"; e acrescenta: "ponto de vista genial, do qual tirou as consequências sem deixar-se levar por jogos dialéticos, sem construir um sistema”. Bergson (1915, p. 15-16) também não lhe poupará elogios: "no começo deste século, a França teve um grande metafísico, o maior já produzido desde Descartes e Malebranche; Maine de Biran [...], chegando ao ponto de podermos perguntar se o caminho que este filósofo abriu não é aquele pelo qual a metafisica deverá marchar definitivamente".

\section{Breves considerações finais}

A psicologia é uma ciência experimental, que traz à luz uma propriedade fundamental do homem: a apercepção. Este não é apenas um ser extenso e sensível; ele apercebe sua existência, e tem consciência de si; contudo, para saber o que realmente apercebemos, é necessário remetermo-nos à origem do exercício desta disposição. A psicologia, como toda ciência, repousa sobre uma experiência originária, que Biran chama de fato primitivo do sentido intimo.

Se Descartes acredita em nos ter dado o primeiro princípio de toda ciência, a primeira verdade evidente por si mesma, ao dizer penso logo sou (algo ou substância pensante), nós faremos melhor, [de maneira] mais tenaz, e desta vez com a evidência irrecusável do sentido íntimo: eu ajo, eu quero, ou eu penso a ação, logo me sinto causa, logo eu sou ou existo realmente a título de causa ou de força. É sob esta relação, precisamente, que meu pensamento interior é a expressão ou a concepção e a produção de minha existência real, ao mesmo tempo que a manifestação primeira e a parição do $e u$, que nasce para si mesmo começa a se conhecer (TISSERAND, 1932, v. XIV, p. 271).

O fato primitivo é, portanto, a origem de todo nosso conhecimento. A psicologia, em Biran, torna-se a ciência fundamental e verdadeira metafisica. $\mathrm{O}$ equívoco foi ignorar que o fato original é a expressão de uma atividade. Consequentemente, Biran (TISSERAND, 1932, v. VII, p. 158) entende que o papel do esforço não foi levado em consideração, visto que, "[...] no fato primitivo, o eu toma consciência de si agindo sobre seu corpo, esta é a expressão ou concepção [...] de minha existência real, percebendo um contraste entre o que causa a ação e a que sofre [...]". Por fim, o primeiro dado psicológico é o eu atuando sobre seu corpo. 
Desconsiderando isto não há como obter avanços numa concepção científica de psicologia.

\section{Referências}

BERGSON, H. La Philosophie Française. Revue de Paris, 1915.

BERTRAND, A. Science et psychologie. Paris: Ernest Leroux, 1887. (Nouvelles oeuvres inédites de Maine de Biran).

COUSIN, V. Nouveaux fragments philosophiques. Cours de l'histoire de la philosophie. Paris. Ed. Bordier, 1864.

GHIO, M. Maine de Biran e la tradizione biraniana in Francia. Torino: Edizioni di Filosofia, 1962.

GOUHIER, H. Les conversions de Maine de Biran. Histoire philosophique du sentiment religieux en France. Paris: J. Vrin, 1947.

GUILLERMIT, L. Leģons sur la Critique de la Raison Pure de Kant. Paris: Vrin, 2008.

HEIMSOETH, H. Transzendentale Dialektik: Ein Kommentar zu Kants Kritik der reinen Vernunft. Berlin: de Gruyter, 1966.

KANT, I. Crítica da Raz̃ão Pura (KrV) Lisboa: Calouste, 2008.

KANT, I. Gesammelte Schriften. Hrsg. Preussische Akademie der Wissenschaften (Bd. 1-22); Deutsche Akademie der Wissenschaften zu Berlin (Bd. 23); Akademie der Wissenschaften zu Göttingen (Bd. 24). Berlin: [s.n.], $1900 \mathrm{ff.}$

KANT, I. Primeiros princípios metafísicos da ciência da natureza (MAN) Lisboa: Edições 70, 2019.

KÖNIG, E. Maine de Biran - der französische Kant. Philosophische Monatshefte, Berlin, Bd. 25, 1889.

LACHELIER, J. Du fondement de l'induction. Paris: Facsimile Publisher, 1871.

OLIVEIRA, A. R. A influência de Johann Nicolaus Tetens na dedução transcendental das categorias de Kant. Orientador: Daniel Omar Perez. Tese (Doutorado em Filosofia) - Instituto de Filosofia e Ciências Humanas, Universidade Estadual de Campinas, Campinas, 2019.

PAIM, A. História das idéias filosóficas no Brasil. São Paulo: Grijalbo; Edusp, 1973.

TISSERAND, P. Oeuvres de Maine de Biran. Paris: Félix Alcan, 1920-1932.

VOUTSINAS, D. La Psychologie de Maine de Biran. Paris. Ed. S.I.P.E, 1975.

RECEBIDO: 23/02/2021

RECEIVED: 02/23/2021

APROVADO: 09/07/2021

APPROVED: 07/09/2021 